\title{
A rare case of carcinoma breast with cerebellar dysfunction paraneoplastic syndrome
}

\begin{abstract}
Paraneoplastic Syndrome, as Paraneoplastic cerebellar degeneration (PCN), in carcinoma breast is a rare entity due to the autoimmune responses. We report a case report of 52 year female with carcinoma breast along with symptoms and signs of cerebellar dysfunction, which on further evaluation is found to be anti-YO autoantibody positive paraneoplastic syndrome. In spite of surgical and chemotherapy patient's neurological condition worsened indicating the poor prognosis of the condition.
\end{abstract}

Keywords: Paraneoplastic syndrome, Yo antibody, Carcinoma breast
Volume 4 Issue 4 - 2016

\author{
Anand Prasath Jayachandiran, \\ Ramasubramanian K, Umarani \\ S,Vijayalakshmi S, Anandi A, \\ Kalyanasundarabharathi VC,Ashok Kumar \\ R, Daniel Ravi Kumar R, Sabarish Kumar G, \\ Prabhakaran U, Sharini venugopal \\ Madras Medical College, India
}

Correspondence:Dr.Anand Prasath Jayachandiran, Madras Medical College, No 16,7th cross street, New street Cheyyar, Postal code $\square$ 604407, Tamil Nadu, India, Tel 988474932I, Email j7anand@gmail.com

Received: February 0I, 20I5 | Published: March 14, 2016
Abbreviations: PCN, Paraneoplastic Cerebellar Degeneration; IDC, Infiltrating Ductal Carcinoma; CSF, Cerebrospinal fluid; Anti YO, anti YO Autoantibodies; ONA, Onconeural Antibody

\section{Introduction}

Paraneoplastic syndrome, which is a rare entity is believed to be initiated by an autoimmune system in response to the underlying malignancy. ${ }^{1}$ Carcinoma breast can be associated with paraneoplastic syndrome in $1-3 \%{ }^{2}$ The association between breast carcinoma and cerebellar dysfuntion as a paraneoplastic syndrome is a known entity, yet a handful of cases have been reported. We present such an association.

\section{Case presentation}

A 52 year female with no past medical history or prolonged drug intake came with complaints of lump in left breast for the past 8 months, which is the progressive sudden onset of difficulty in walking for the past week along with slurring of speech, giddiness, which was progressive. There was no disturbance in bowel or bladder habits or any symptoms of focal or profound neurological deficit. On examination patient, the breast lump was clinically consistent with carcinoma present in the upper outer and central quadrant and was clinically Stage IIIa (T3N1M0) had nystagmus, dysarthria, dysdiadokinesia, past pointing, pendullar knee jerk suggestive of cerebellar dysfunction.

Biopsy of the breast revealed Infiltrating Ductal Carcinoma -Not Otherwise Specified- Grade II with ER Negative; PR weakly positive and Her-2neu Strongly positive (Figure 1). Metastatic workup including, USG abdomen, CTabdomen\&chest, Bone scans all turned out negative for metastasis. MRI brain was taken to rule out metastasis, which showed cerebellar atrophy with no evidence of metastasis (Figure 2). CSF analysis was done, which was normal with no abnormalities. Anti YO autoantibodies was sort which was strongly positive. As per our Tumor board policy patient received 4 cycles of Chemotherapy, as neoadjuvant therapy and the lump responded well to treatment and almost disappeared. The chemo regimen being
5-FU,Adriamycin and cyclophosphamide. The patient was put on a course of steroids. But the neurological symptoms progressed. Later the patient was operated, modified radical mastectomy was done (Figure 3). Post-op pathological report came as IDC-NOS in a small area. Yet the patient's neurological symptoms progressed and became wheelchair bound.

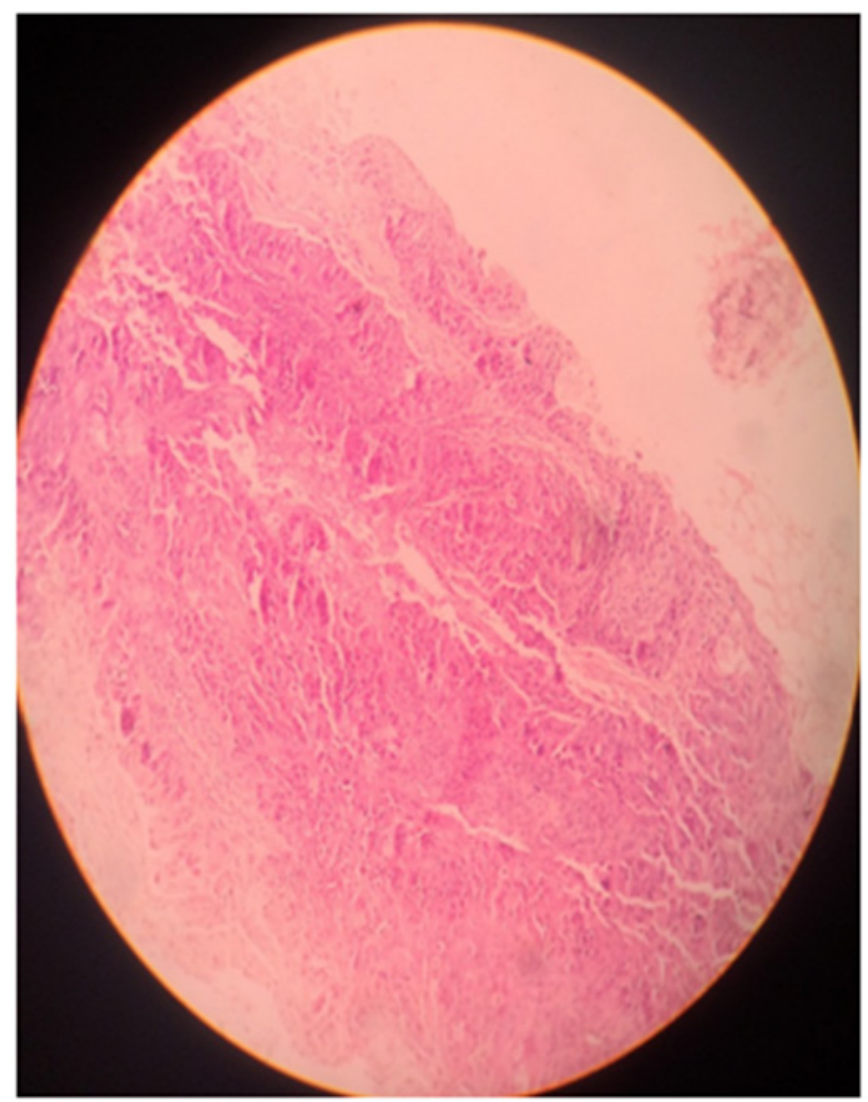

Figure I Ductal Carcinoma. 


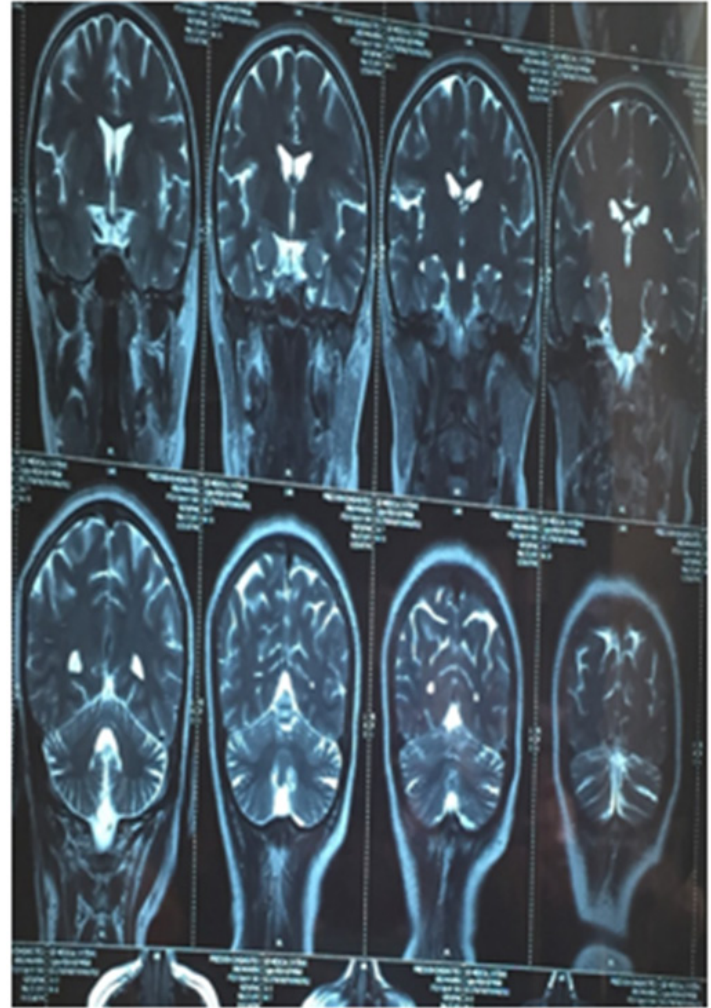

Figure $2 \mathrm{MRI}$ of the patient showing cerebellar atrophy.

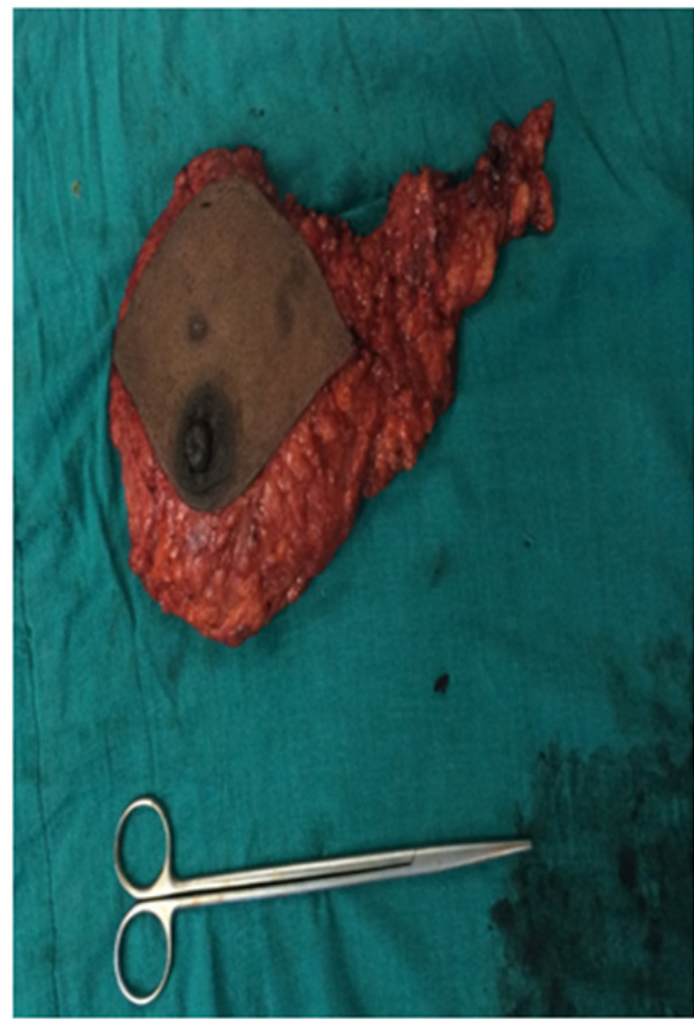

Figure 3 Surgical Specimen.

\section{Discussion}

The association between breast malignancy and cerebellar degeneration, paraneoplastic syndrome, was first identified in 1938 and the syndrome was fully described by Brain in $1951 .^{3}$ It is because of the autoimmune response, with onco-neural antibodies (ONA) targeted against the onco-neural antigens shared by tumor cells and nervous tissue. Anti-Yo antibody is the most common ONA associated with PCD followed by anti-Hu, anti-Tr and anti-Ri Cdr2, also known as Purkinje neuronal protein, is expressed on cells within the cerebellum and is similar to the tumour antigen that is expressed in breast and ovarian tumours for anti-Yo antibody. ${ }^{6}$

Cross-reaction between the ONAs and normal proteins occur, resulting in abnormal immune- mediated responses that cause cerebellar injury and neuronal dysfunction. The feature of cerebellar ataxia due to PCD in carcinoma breast usually precedes the tumor lump in $60 \%$ of cases. ${ }^{7}$ But in our case the lump preceded the symptoms of cerebellar dysfunction. Confirmation of PCD requires ruling out metastasis by imaging and CSF analysis and antibody level evaluation.

MRI brain in the early stages will mostly be normal and in advanced stages may Show cerebellar atrophy. ${ }^{8,9}$ This atrophic changes was seen in our patient. CSF analysis in the majority of PCD patients shows lymphocytic pleocytosis and elevated protein level. ${ }^{10}$ In our patient the CSF analysis showed no abnormality. As previously mentioned Anti YO levels will be detected in PCD which will be absent in otherwise normal individual. It has been quoted that $40 \%$ of PCD presents with negative antibody status. ${ }^{11}$ It appears negative antibody in PCD is a good prognostic feature. In our patient the antibody level was strongly positive and the patient's status deteriorated in spite of the measures. This was in accordance with some of the previous literature. ${ }^{12}$

Clinical progression is variable with median survival, as quoted in some studies, is about 100 months for carcinoma breast with PCD. ${ }^{13}$ The patient in our report is more in line with the literature. The patients' neurological symptoms progressed in spite of chemotherapy, steroids and surgical removal of the initiating tumor and became wheelchair bound. Various lines of treatment, including plasmapheresis, immunoglobulin, have been used. The roles of these treatments are yet questionable with poor outcomes in antibody positive PCD patients.

\section{Acknowledgments}

None.

\section{Conflicts of interest}

There is no conflict of interest among the authors.

\section{References}

1. Pittock SJ, Kryzer TJ, Lennon VA. Paraneoplastic antibodies coexist and predict cancer, not neurological syndrome. Ann Neurol. 2004;56(5):715719

2. Gatti G, Simsek K, Kurne A. Paraneoplastic neurological disorders in breast cancer. Breast 12(3): 203-207.

3. Rees JH (2004) Paraneoplastic syndromes: when to suspect, how to confirm, and how to manage. J Neurol Neurosurg Psychiatry. 2003;75( Suppl 2):ii43-ii50.

4. Furneaux HM, Rosenblum MK, Dalmau J, et al. Selective expression of Purkinje-cell antigens in tumour tissue from patients with paraneoplastic cerebellar degeneration. N Engl J Med. 1990;322(26):1844-1851.

5. Rojas-Marcos I, Rousseau A, Keime-Guibert F, et al. Spectrum of paraneoplastic neurologic disorders in women with breast and gynaecologic cancer. Medicine (Baltimore). 2003;82(3):216-223. 
6. Schmahmann JD, Sherman JC. The cerebellar cognitive affective syndrome. Brain. 1998;121(Pt4):561-579.

7. Storstein A, Vedeler CA. Paraneoplastic neurological syndromes and onconeural antibodies: clinical and immunological aspects. Adv Clin Chem. 2007;44:143-185.

8. de Andres C, Esquivel A, de Villoria JG, et al. Unusual magnetic resonance imaging and cerebrospinal fluid findings in paraneoplastic cerebellar degeneration: a sequential study. J Neurol Neurosurg Psychiatry. 2006;77(4):562-653.

9. Schied R, Voltz R, Briest S, et al. Clinical insights into paraneoplastic cerebellar degeneration. $J$ Neurol Neurosurg Psychiatry. 2006;77(4):529-530.
10. Peterson K, Rosenblum MK, Kotanides H, et al. Paraneoplastic cerebellar degeneration. I. A clinical analysis of 55 anti-Yo antibodypositive patients Neurology. 1992;42(10):1931-1937.

11. Posner JB, Dalmau J. Paraneoplastic syndromes. Curr Opin Immunol. 1997;9(5):723-729.

12. Ng YR, Ho CD, Ng WL, et al. Paraneoplastic cerebellar degeneration and dermatomyositis as first manifestations of underlying breast malignancy: a report of two cases and a brief review of the subject. Surg Case Rep. 2015;1(1):59.

13. Rojas I, Graus F, Keime-Guibert F, et al. Long-term clinical outcome of paraneoplastic cerebellar degeneration and anti-Yo antibodies. Neurology. 2000;55(5):713-715. 